University of Nebraska - Lincoln

DigitalCommons@University of Nebraska - Lincoln

Faculty Publications - Textiles, Merchandising and Fashion Design

Textiles, Merchandising and Fashion Design,

Department of

2009

Citric acid cross-linking of starch films

Narendra Reddy

University of Nebraska - Lincoln, nreddy3@unl.edu

Yiqi Yang

University of Nebraska - Lincoln, yyang2@unl.edu

Follow this and additional works at: https://digitalcommons.unl.edu/textiles_facpub

Part of the Art and Design Commons

Reddy, Narendra and Yang, Yiqi, "Citric acid cross-linking of starch films" (2009). Faculty Publications Textiles, Merchandising and Fashion Design. 25.

https://digitalcommons.unl.edu/textiles_facpub/25

This Article is brought to you for free and open access by the Textiles, Merchandising and Fashion Design, Department of at DigitalCommons@University of Nebraska - Lincoln. It has been accepted for inclusion in Faculty Publications - Textiles, Merchandising and Fashion Design by an authorized administrator of DigitalCommons@University of Nebraska - Lincoln. 


\title{
Citric acid cross-linking of starch films
}

\author{
Narendra Reddy ${ }^{1}$ and Yiqi Yang ${ }^{1,2,3}$
}

1. Department of Textiles, Clothing and Design, University of Nebraska-Lincoln

2. Department of Biological Systems Engineering, University of Nebraska-Lincoln

3. Nebraska Center for Materials and Nanoscience, University of Nebraska-Lincoln

Corresponding author - Y. Yang, Department of Biological Systems Engineering, 234, HECO Building, East Campus, University of Nebraska-Lincoln, Lincoln, NE 68583-0802, USA; tel 402 472-5197, fax 402 472-0640, email yyang2@unl.edu

\begin{abstract}
This paper shows that citric acid can cross-link starch and improve the tensile strength, thermal stability and decrease the dissolution of starch films in water and formic acid. The poor mechanical properties and water stability of starch have restricted its industrial applications. Although cross-linking is a common approach to improve the properties of starch products, current starch cross-linking methods are either expensive, toxic or do not impart the desired properties to the cross-linked materials. In this research, the possibility of cross-linking starch films using citric acid to improve their strength and stability was examined. Citric acid cross-linked starch films show about $150 \%$ higher strength than non-cross-linked films and have strength better than most cross-linked starch and synthetic polymer blended films previously developed. Films cross-linked with 5\% citric acid had only 35\% loss in weight after being in formic acid for $5 \mathrm{~h}$ at $50{ }^{\circ} \mathrm{C}$ whereas the non-cross-linked films dissolved immediately.
\end{abstract}

Keywords: starch, film, cross-linking, citric acid, dissolution, tensile strength

\section{Introduction}

Cross-linking is a common approach to improve the performance of starch for various applications. Starch and starch products have been cross-linked with cross-linking agents, such as phosphorus oxychloride, sodium trimetaphosphate, sodium tripolyphosphate, epichlorohydrin, and 1,2,3,4-diepoxybutane, to improve the mechanical properties and water stability of starch products (Hirsch and Kokini, 2002; Kunaik and Marchessault, 1972; Seker and Hanna, 2006; Simkovic et al., 2004; Wattanachant et al., 2003). In addition to cross-linking, blending starch with synthetic polymers has also been considered to improve the performance of starch products. Films have been developed from starch blended with low-density polyethylene, and poly(vinyl alcohol) (Kim and Lee, 2002; Raj et al., 2004; Ramaraj, 2007). The mechanical properties and dissolution of the blend films showed substantial improvement compared to the non-cross-linked films (Kim and Lee, 2002; Ramaraj, 2007). However, the chemicals used for cross-linking starch are relatively toxic, expensive or do not provide the desired improvement in properties. Blending synthetic polymers with starch at high temperatures could damage starch and lead to poor properties of the materials developed.

Poly(carboxylic acids), such as citric acid, are inexpensive and non-toxic chemicals that have been used to improve the performance properties of cellulose and proteins in textile ap- plications (Yang et al., 1991, 1996, 1997; Yang and Wang, 1996). Although cotton and silk fabrics have been cross-linked with carboxylic acids, mainly to improve their appearance and resistance to wrinkling, it has also been shown that the mechanical properties and water stability of regenerated protein fibers can be improved by cross-linking with poly(carboxylic acids) (Yang et al., 1996). A schematic of the conventional cross-linking of cellulose with carboxylic acids is shown in Scheme 1 (Yang et al., 1996, 1997). As seen from the scheme, carboxylic acids cross-link the hydroxyl groups in cellulose and the crosslinking reaction is reported to occur at temperatures between 165 and $175^{\circ} \mathrm{C}$ (Yang et al., 1996, 1997).

As seen from Scheme 1, poly(carboxylic acids) cross-linking of cellulose occurs mainly through the hydroxyl groups. Since starch also contains considerable amounts of hydroxyl groups and starch is more easily accessible to chemicals than cellulose, poly(carboxylic acids) can be expected to cross-link starch and improve its properties.

Although citric acid has not been used to cross-link starch, it has been reported that citric acid can form strong hydrogen bond interactions with starch and improves its thermal and water stability and inhibit retrodegradation (Yu, Wang, \& Ma, 2005). However, incorporating citric acid substantially reduced the tensile stress of the products developed under the conditions used (Yu et al., 2005). Citric acid was also used an additive to starch-PVA films, due to the antibacterial and 
<smiles>CC(C(=O)O)C(C)(C)C(=O)O</smiles><smiles>[R][R]1OC(=O)[C@H](C)[C@]1(C)C(=O)O</smiles><smiles>[R]OC(=O)C1(C)C(C)C(=O)OC1C(=O)O</smiles><smiles>[R]OC(=O)C(C)C1(C)C(=O)O[R]([R])OC1C</smiles><smiles>[R]OC(=O)[C@H](C)[C@@]1(C)C(=O)OC(=O)[C@H]1C</smiles>

Scheme 1. Mechanism of the conventional dry cross-linking of cellulose using carboxylic acids in the presence of acid catalysts. R represents cellulose (Yang and Wang, 1996; Yang et al., 1997).

acidulant effects of citric acid. It was reported that adding citric acid decreased the strength of the starch-PVA film but provided better strength than glycerol-added starch-PVA films. The better strength of the citric acid-added starch-PVA film compared to glycerol-added starch-PVA films was attributed to the better hydrogen bonding between citric acid and starchPVA molecules compared to glycerol and starch-PVA molecules (Yoon et al., 2006, 2007).

In this research, we show that citric acid can cross-link starch and improve the mechanical properties and decrease dissolution of starch in water and formic acid. The effect of various amounts of citric acid and glycerol used on the mechanical properties of the films and changes in the morphology and physical structure, thermal stability, water vapor permeability, and color and stability of the films in water and formic acid has been studied.

\section{Materials and methods}

\subsection{General}

Commercially-available corn starch was purchased from American Maize Products Co., Hammond, IN). Glycerol, citric acid, sodium hypophosphite, sodium hydroxide and acetic acid were reagent-grade chemicals purchased from VWR International, Bristol, CT.

\subsection{Preparing starch films}

Starch films were prepared by dispersing 3\% (w/w) starch in water. The starch dispersion was heated on a hot plate to $90^{\circ} \mathrm{C}$ and held at that temperature for $20 \mathrm{~min}$. The heated starch solution was cooled to about $65^{\circ} \mathrm{C}$ and the required amount of glycerol was added to the starch solution. The starch solution was then poured onto Teflon-coated glass plates. The cast starch films were allowed to air dry for about $48 \mathrm{~h}$ before peeling them from the plates.

\subsection{Cross-linking starch films}

A specified amount of citric acid and the catalyst sodium hypophosphite $(50 \% \mathrm{w} / \mathrm{w}$, on weight of citric acid used) was dissolved in the starch solution. The starch solution containing the cross-linking agent and catalyst was heated to $90{ }^{\circ} \mathrm{C}$, held at that temperature for $20 \mathrm{~min}$, then cooled to $65^{\circ} \mathrm{C}$ and poured onto Teflon-coated glass plates. The cast films were allowed to air dry for about $48 \mathrm{~h}$ and later peeled from the plates. The starch films were then treated in a hot air oven at $165^{\circ} \mathrm{C}$ for various periods of time for the cross-linking reaction to occur. After heating, the films were immediately transferred to a conditioning chamber maintained at $23{ }^{\circ} \mathrm{C}$ and $50 \%$ relative humidity.

\subsection{Tensile properties}

The tensile properties of the starch films were determined on an MTS tensile tester (QTest 10; MTS, Eden Prairie, MN) according to ASTM standard D 882-02. Testing was done on five samples each measuring $10 \mathrm{~cm} \times 1 \mathrm{~cm}$ randomly cut from the cast films. Two replications were done for a total of 10 tests for each condition. Before testing, all samples were conditioned for at least $40 \mathrm{~h}$ in a conditioning chamber maintained at $23 \pm 0.5^{\circ} \mathrm{C}$ and $50 \pm 1 \%$ relative humidity.

\subsection{Fourier-transform infrared}

FTIR spectra were collected from the non-cross-linked and cross-linked starch films on an attenuated total reflectance ATR spectrophotometer (Nicolet 380; Thermo-Fisher, Waltham, MA). The samples were thoroughly washed in water to remove unattached citric acid and catalysts. The washed samples were placed on a germanium plate and 128 scans were collected for each sample.

\subsection{Thermal analysis}

A differential scanning calorimeter (DSC 822; Mettler-Toledo Inc., Columbus, $\mathrm{OH}$ ) and a thermogravimetric analyzer (Leco TGA 701; Leco, St Joseph, MI) were used to study the thermal behavior of the starch films before and after cross-linking. DSC curves were obtained by heating the samples at a rate of $20^{\circ} \mathrm{C}$ per minute and holding at $50^{\circ} \mathrm{C}$ for $3 \mathrm{~min}$ to remove moisture and then to $250{ }^{\circ} \mathrm{C}$ at $20^{\circ} \mathrm{C}$ per minute. The samples were then cooled to $25^{\circ} \mathrm{C}$ and a second heating cycle was performed by heating the samples again to $250{ }^{\circ} \mathrm{C}$ at $20^{\circ} \mathrm{C}$ per minute. Thermogravimetric analysis was performed by heating the sample at a rate of $15^{\circ} \mathrm{C}$ per minute.

\subsection{Morphological structure}

The surface features of the non-cross-linked and cross-linked films were observed using a scanning electron microscope (Hitachi Model S3000N Variable Pressure SEM; Hitachi Ltd., Tokyo, Japan). The samples were sputter coated with gold palladium and observed under the SEM at a voltage of $15 \mathrm{kV}$.

\subsection{Water vapor permeability}

The water vapor permeability of the control and cross-linked starch films was determined according to ASTM standard E96/E96M-05. Three replications were done for the control and cross-linked films and the average water vapor permeability is reported along with \pm one standard deviation.

\subsection{X-ray diffraction}

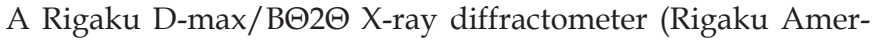
icas, Woodlands, TX) with Bragg-Brentano parafocusing geometry, a diffracted beam monochromator, and a copper target X-ray tube set to $40 \mathrm{kV}$ and $30 \mathrm{~mA}$ was used to observe the diffraction pattern of the control and cross-linked starch films. The diffraction patterns were recorded for $2 \theta$ values ranging from $5^{\circ}$ to $40^{\circ}$ on samples measuring $2 \mathrm{~cm} \times 2 \mathrm{~cm}$. 
Figure 1. Effect of adding glycerol on the strength and elongation of cross-linked starch films. Films were cast from $3 \%$ starch and cross-linked using $5 \%(\mathrm{w} / \mathrm{w})$ citric acid and cured at $165^{\circ} \mathrm{C}$ for $5 \mathrm{~min}$.

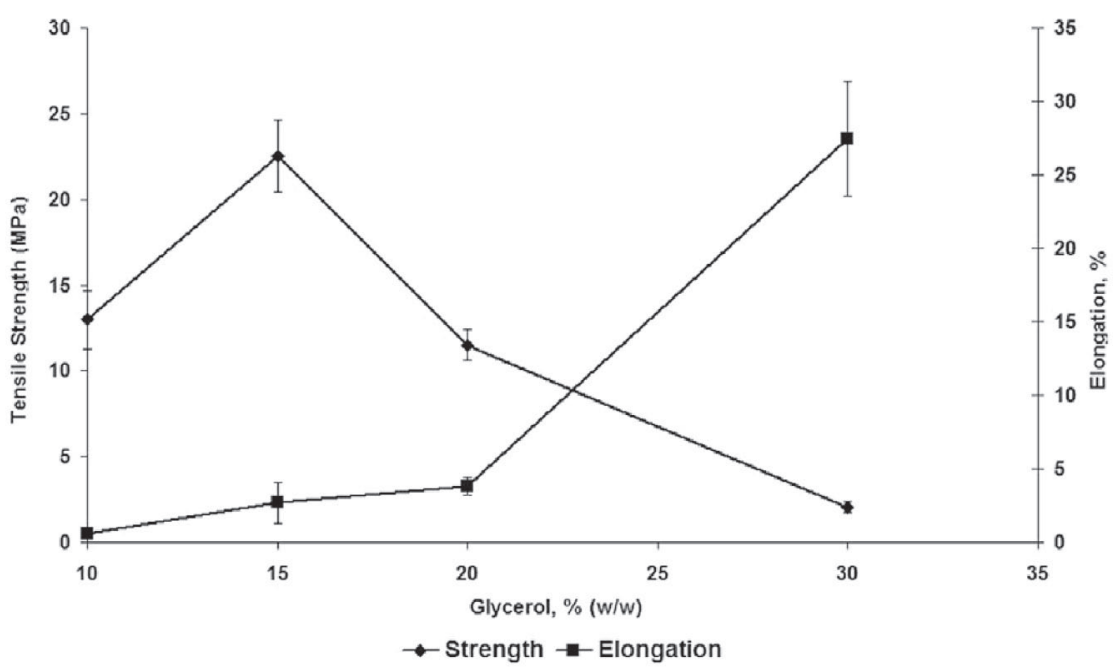

\subsection{Changes in color}

The changes in the color of the starch films due to cross-linking were measured in terms of the yellowness index $(Y I)$ using a spectrophotometer (Hunter Lab, Model: Ultra scan XE; Hunter Associates Laboratory Inc., Reston, VA) with a 1-inch opening and D65/10 observer. The film samples conditioned in the standard testing atmosphere were folded in the middle and the two layers were used for measurement. Three readings were taken from three different places in each film and the measurements were repeated on three films that were cast separately. The average and standard deviations of the $Y I$ are reported.

\subsection{Weight loss in water under various $p H$ conditions}

The control and cross-linked starch films were treated in phosphate-buffered saline water $(\mathrm{pH} 7.2)$ at $50{ }^{\circ} \mathrm{C}$ for $3-35$ days. About $0.5 \mathrm{~g}$ of the films were put in water (1:5 film to water ratio) and taken out after a specified time. The samples taken out were rinsed in distilled water and allowed to dry in a standard conditioning chamber maintained at $23 \pm 0.5{ }^{\circ} \mathrm{C}$ and $50 \pm 1 \%$ relative humidity. The weight of the conditioned specimen after treating in water was used to determine the $\%$ weight loss of the films in water.

\subsection{Weight loss in formic acid}

The weight loss of the non-cross-linked and cross-linked starch films in formic acid was studied at two temperatures $\left(20\right.$ and $50{ }^{\circ} \mathrm{C}$ ). Precisely $0.2 \mathrm{~g}$ of the films were put in $5 \mathrm{~g}$ of formic acid in glass vials and sealed. The vials were kept at $20{ }^{\circ} \mathrm{C}$ for $24 \mathrm{~h}$ and at $50{ }^{\circ} \mathrm{C}$ for $5 \mathrm{~h}$. After the treatment, the formic acid was removed and the remaining starch was thoroughly washed in distilled water. The dry weight of the samples after formic acid treatment was recorded to calculate the $\%$ weight loss. Two replications were repeated for each condition and the average and standard deviation are reported.

\section{Results and discussion}

\subsection{Effect of adding glycerol}

The effect of adding glycerol on the tensile strength and elongation of the cross-linked starch films is shown in Figure 1. Both the control and cross-linked films with less than $10 \%$ glycerol became brittle after curing and were not considered for further studies. Increasing the concentration of glycerol to $15 \%$ from $10 \%$ increases the tensile strength and elongation and provides flexible films. Further increase in glycerol concentration above $15 \%$ increased the elongation but considerably decreased the tensile strength of the films. A glycerol concentration of $15 \%$ provided the highest tensile strength to the films and was used for all further studies. At low concentrations of glycerol $(<10 \%)$, there is not enough plasticizing effect and the starch molecules become brittle. At concentrations above $15 \%$ the plasticizing effect is too pronounced and makes the starch molecules move easily, leading to high elongation but decrease in tensile strength. The amount of glycerol to be added should be decided based on the tensile strength and elongation required for a particular application.

\subsection{Effect of curing time}

The effect of curing time on the tensile strength of the citric acid cross-linked films is shown in Figure 2. As seen from the figure, there is a narrow range of curing time (3-5 min) that provides the optimum tensile strength to the films. Further increase in curing time substantially decreases the tensile strength of the films at this curing temperature. Curing time is one of the most important factors determining the efficiency of carboxylic acid cross-linking and hence the properties of the cross-linked materials. Sufficient curing time is necessary for the cross-linking reaction to occur but excess curing will damage the starch molecules, leading to decrease in tensile strength and unwanted changes in the color of the films. An optimum curing time of about $5 \mathrm{~min}$ at about $165-170{ }^{\circ} \mathrm{C}$ was also reported for citric acid cross-linking of cotton fabrics. Although longer curing times may be suitable, if lower curing temperatures are used, it is more preferable to have shorter curing times for large-scale processing of films, due to economic and technical reasons. Since the citric acid cross-linking of starch occurs at high temperatures, a one-step cross-linking process may be possible, in order to develop cross-linked starch products by extrusion.

\subsection{Effect of citric acid concentration}

Cross-linking starch films with citric acid improved the tensile strength of the films by more than $150 \%$, as seen from Figure 3 . However, there is an optimum amount of citric acid that is necessary to obtain good increase in the tensile strength of the films. Concentrations of citric acid less than $5 \%$ provided 
Figure 2. Effect of curing time on the strength of cross-linked starch films. Films were cast from 3\% starch and cross-linked using 5\% (w/w) citric acid.
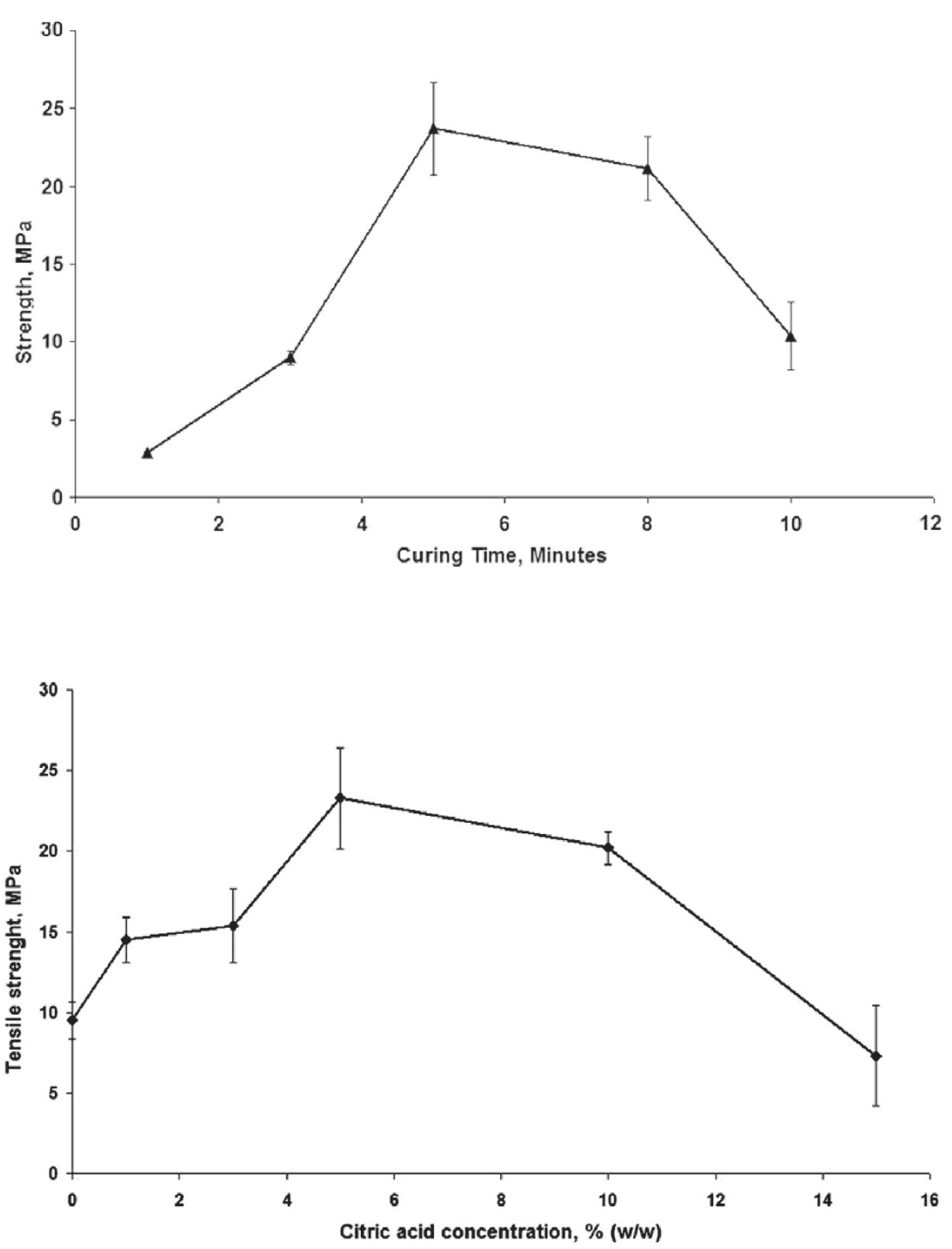

Figure 3. Effect of increasing citric acid concentration on the strength of cross-linked starch films. Films were cast from 3\% starch with 15\% glycerol and cured at $165^{\circ} \mathrm{C}$ for $5 \mathrm{~min}$. relatively low improvement in tensile strength and concentrations above 5\% decreased the tensile strength of the films. Cross-linking interconnects the starch molecules in the film, which could increase the molecular weight of the starch and also provides better intermolecular interactions between molecules, leading to better tensile strength, compared to the noncross-linked starch films. At low concentrations of citric acid, there is not enough cross-linking between the starch molecules to improve the tensile strength of the films. At high concentrations, however, there is excess cross-linking that limits the mobility of the starch molecules, leading to lower tensile strength (Yang et al., 1996, 1997).

Previously, high amylose starch films cross-linked with epichlorohydrin $(6 \%)$ had tensile strength of about $38 \mathrm{MPa}$, higher than the strength of the films obtained in this research but normal starch was used to produce the films in this research (Rioux, Ispas-Szabo, Ait-Kadi, Mateescu, \& Juhasz, 2002). Apart from the report on cross-linking high amylose starch films, to the best of our knowledge, there is no literature available on cross-linking pure starch films. Most of the cross-linked starch films reported in the literature are blends of cross-linked starch with synthetic polymers. Films made using epichlorohydrin-cross-linked starch and polyethylene (1:1 ratio) had strength ranging from 12 to $15 \mathrm{MPa}$ with varying amounts of epichlorohydrin (0.1-2\%), compared to $24 \mathrm{MPa}$ for the $5 \%$ citric acid cross-linked films (Kim \& Lee, 2002). Sim- ilarly, starch-polyethylene films cross-linked with boric acid $(0.5-2.5 \%)$ had tensile strength ranging from 8.9 to $10.1 \mathrm{MPa}$ and the breaking elongation decreased from $60 \%$ to $8 \%$ after cross-linking (Yin, Li, Liu, \& Li, 2005). However, starchpolyvinyl alcohol films cross-linked with hexamethoxymethylmelamine had tensile strength ranging from 50 to $65 \mathrm{MPa}$, and the non-cross-linked films also had high strengths, ranging from 45 to $55 \mathrm{MPa}$ (Chen, Imam, Gordon, \& Greene, 1997). In another report, starch-LDPE films made using epichlorohydrin cross-linked and/or glycerol modified starch had strength ranging from 5 to $14 \mathrm{MPa}$ (Garg \& Jana, 2007). Using high amylose starch or other poly(carboxylic acids) may be two approaches to further increase the strength of the starch films developed in this research.

\subsection{FTIR}

The FTIR spectra of the non-cross-linked films and films crosslinked with 5\% citric acid are shown in Figure 4. Both the films have similar peaks, except for the additional peak in the crosslinked film at $1724 \mathrm{~cm}^{-1}$. The band at $1724 \mathrm{~cm}^{-1}$ (indicated by an arrow in Figure 4) is ascribed to the carboxyl and ester carbonyl bands (Yang et al., 1991). Since the films were thoroughly washed to remove the unbound citric acid and catalyst, the presence of the carbonyl peak confirms the chemical linkages between citric acid and starch. 
Figure 4. FTIR spectra of the noncross-linked starch films and starch films cross-linked with $5 \%$ citric acid.

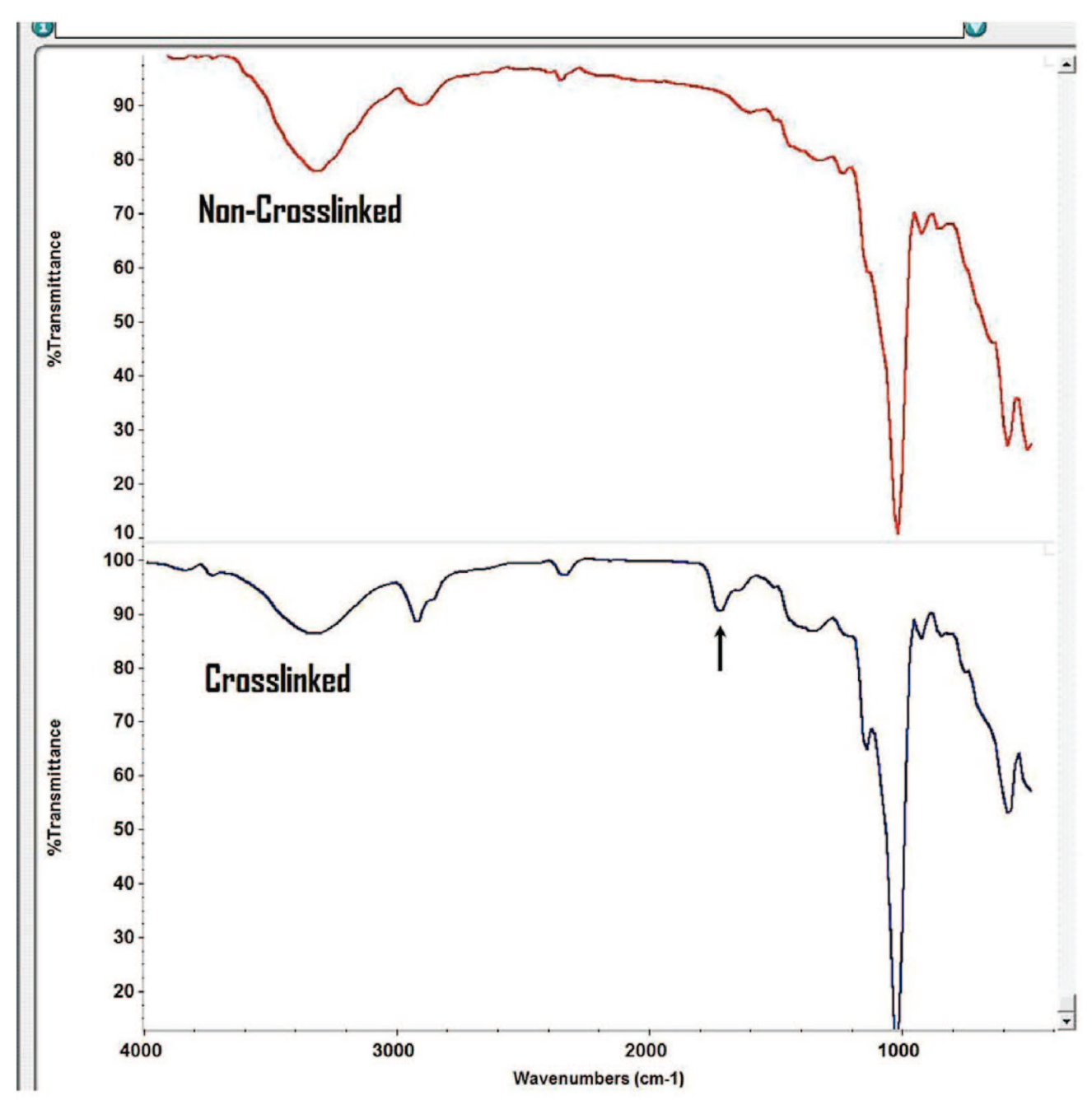

of the starch molecules after cross-linking. However, the crosslinked films showed a higher weight loss than the non-crosslinked films between 220 and $320^{\circ} \mathrm{C}$. This is probably due to the degradation of some of the starch molecules in the crosslinked films when they were cured at high temperatures for the cross-linking reaction to occur. The cross-linked films have much higher thermal stability than the non-cross-linked films above $320^{\circ} \mathrm{C}$, due to the cross-linking of the starch molecules.

\subsection{Morphological structure}

Scanning electron microscope pictures of the control and cross-linked films do not show any appreciable change in surface morphology due to cross-linking, as seen from Figure 7a and $b$, respectively. The films are homogenous without pores or cracks and the starch molecules have been well dispersed without the many granules that were observed in films made from epichlorohydrin cross-linked starch mixed with low-density polyethylene (Garg \& Jana, 2007).

\subsection{Physical structure}

X-ray diffraction patterns of the cross-linked and non-crosslinked starch are similar, with two prominent peaks at about $17^{\circ}$ and $22^{\circ}$, as seen from Figure 8 . However, typical starch peaks seen at about $5^{\circ}$ and $14^{\circ}$ were not seen in either crosslinked or non-cross-linked film, indicating changes in crystallinity and/or the crystal structure. The control and crosslinked starch films had similar \% crystallinity of about $17 \%$ films. The lower weight loss of the cross-linked films between 120 and $220^{\circ} \mathrm{C}$ should be due to the higher thermal stability 
Figure 5. DSC thermograms of the non-cross-linked starch films and starch films crosslinked with $5 \%$ citric acid during the first (a) and second (b) heating cycles.
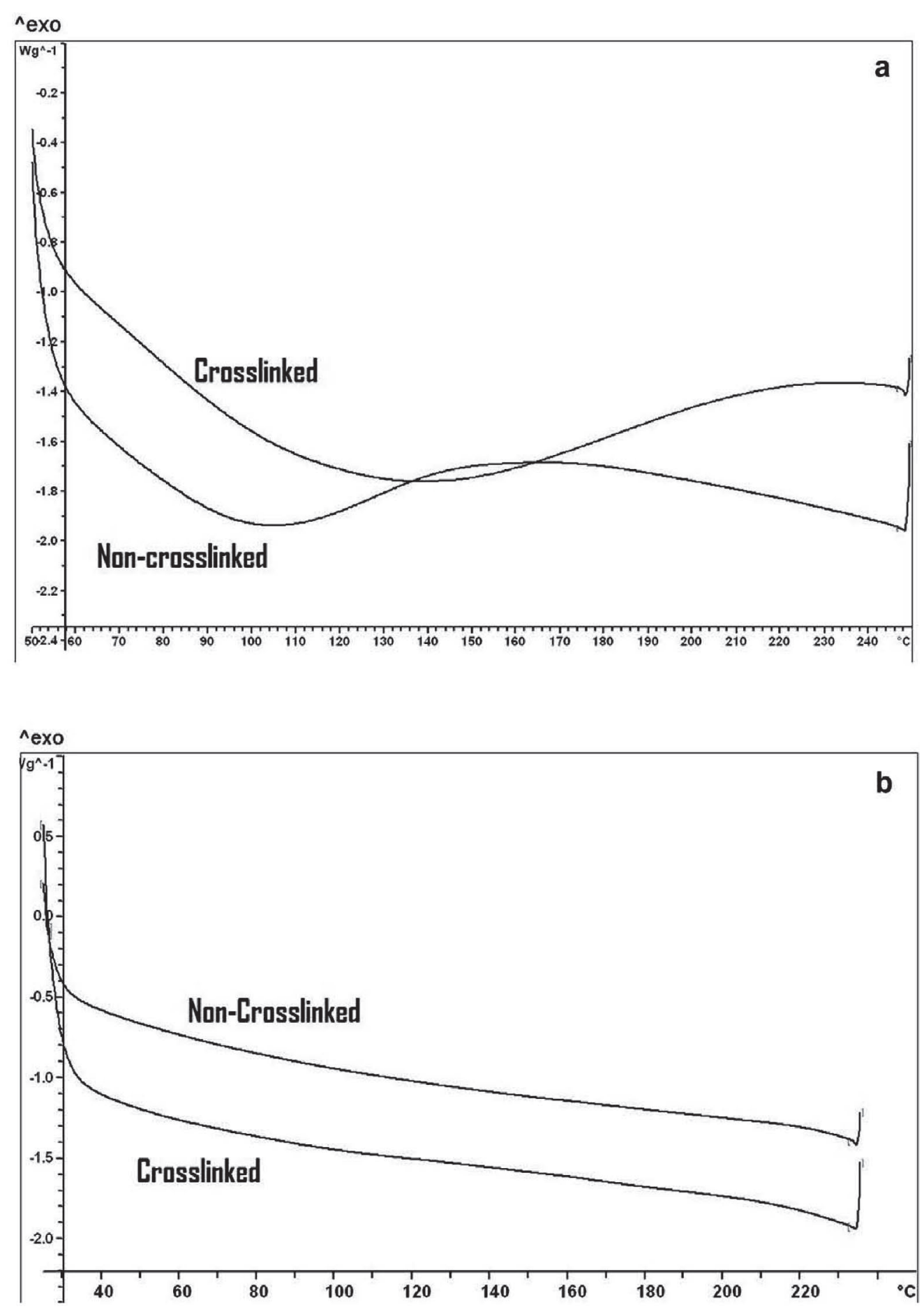

and 14\%, respectively. Epichlorohydrin cross-linked starch films also did not show any change in \% crystallinity or peak positions, compared to native starch (Garg and Jana, 2007; Kim and Lee, 2002). The increase in the diffraction intensity of the cross-linked starch films but decrease in the \% crystallinity suggests that some of the amorphous regions may be better oriented after cross-linking.

\subsection{Water vapor permeability}

Citric acid cross-linked films have slightly lower water vapor permeability, compared to the non-cross-linked films. The control and cross-linked films had a water vapor permeability of $33 \pm 0.5$ and $31 \pm 0.8 \mathrm{~g} \mathrm{~h}^{-1} \mathrm{~m}^{-2}$, respectively. The formation of a more tight structure after cross-linking prevents the swelling of starch and also restricts the movement of molecules, leading to a decrease in the water vapor permeability.

\subsection{Color change}

Citric acid cross-linking is reported to cause yellowing, especially in proteins when cured at high temperatures and/or long periods of time (Schramm et al., 2002; Yang et al., 1996). The changes in the $Y I$ of the starch films before and after curing 
Figure 6. Weight-loss (\%) of the non-cross-linked starch films and starch films cross-linked with 5\% citric acid in a thermogravimetric analyzer.

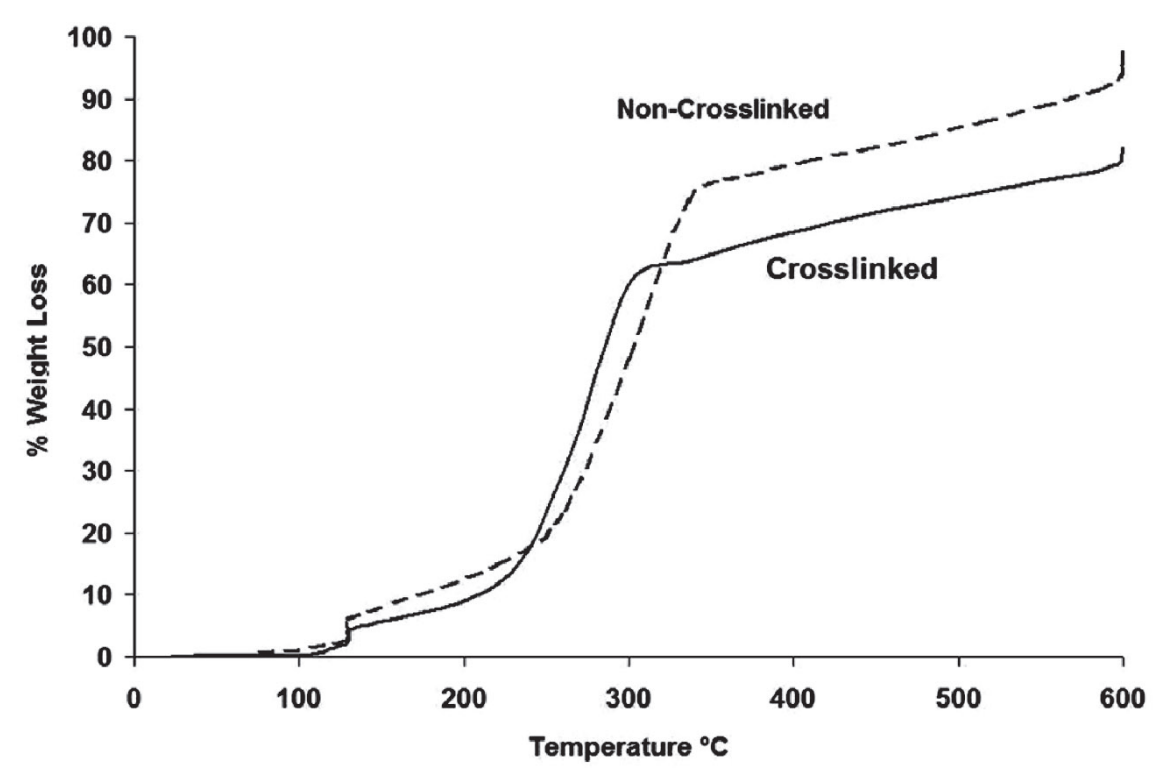

films after curing at high temperatures is mainly due to the dehydration of citric acid that leads to the formation of an unsaturated acid that imparts color to the films (Andrews \& Welch, 1989). The higher the amount of citric acid in the films is, the higher the quantities of unsaturated acids formed, leading to more yellowness. In addition to the formation of the unsaturated acids, starch will also degrade to a certain extent at high temperatures, leading to discoloration, as seen from the higher $Y I$ of the non-cross-linked films after curing, compared to the $Y I$ of the non-cross-linked films before curing.

\subsection{Weight loss in water}

The cross-linked starch films had only about $25 \%$ weight loss, even after being in $\mathrm{pH} 7.2$ water at $50{ }^{\circ} \mathrm{C}$ for 35 days, whereas the non-cross-linked fibers lost about $75 \%$ of their weight, as seen from Figure 10. After 3 days in water, both the crosslinked and non-cross-linked fibers lose about $25 \%$ of their weight. On further treatment in water, the cross-linked fibers do not show any considerable loss in weight but the weight loss of the non-cross-linked films increases to about $70 \%$ after 10 days in water. The non-cross-linked fibers do not experience much weight loss on further treatment in water for up to 35 days. Cross-linking not only increases the strength of the films but also creates a more dense structure. This prevents the swelling of starch and decreases the accessible regions, leading to an improvement in the resistance to dissolution, compared to the non-cross-linked films.

\subsection{Weight loss in formic acid}

The weight loss of starch films in formic acid decreases considerably after cross-linking, as seen from Figure 11. The noncross-linked starch films lose about $50 \%$ of their weight after being in formic acid for $24 \mathrm{~h}$ at $20{ }^{\circ} \mathrm{C}$. Films cross-linked with $1 \%$ and $3 \%$ formic acid have weight loss of about $25 \%$ and those cross-linked with $5 \%$ and $10 \%$ citric acid have weight loss of $17 \%$ and $15 \%$, respectively, when treated in formic acid for $24 \mathrm{~h}$ at $20^{\circ} \mathrm{C}$. The non-cross-linked and films crosslinked with $1 \%$ citric acid completely dissolved in formic acid when treated with formic acid at $50{ }^{\circ} \mathrm{C}$ for $5 \mathrm{~h}$. Films crosslinked with higher amounts of citric acid showed substantial decrease in weight loss in formic acid at $50{ }^{\circ} \mathrm{C}$. Starch films cross-linked with $3 \%$ and $5 \%$ citric acid had weight loss of $53 \%$

and $36 \%$, respectively whereas $10 \%$ and $20 \%$ citric acid cross- with $20 \%$ citric acid have nearly 13 times higher YI than that of the non-cross-linked films after curing. The discoloration of the are shown in Figure 9. There is no change in the YI of the starch films with various amounts of citric acid before curing. After curing at $165^{\circ} \mathrm{C}$ for $5 \mathrm{~min}$, the films turn slightly yellow, wit films. The non-cross-linked films also show a slight increase acid have similar $Y I$, about $10 \%$ higher than their corresponding $Y I$ before curing. The $Y I$ of the films treated with $10 \%$ citric acid increases substantially after curing and those treated 
Figure 8. Diffraction patterns of cross-linked and non-cross-linked starch films show similar diffraction peaks and intensities without any considerable change in the starch crystals due to cross-linking.

Figure 9. Changes in the yellowness index of the starch films before and after curing at $165^{\circ} \mathrm{C}$ for 5 min with various amounts of citric acid.

Figure 10. Weight-loss (\%) of the non-cross-linked and cross-linked starch films after treating in $\mathrm{pH}$ 7.2 water at $50{ }^{\circ} \mathrm{C}$ for various periods of time.
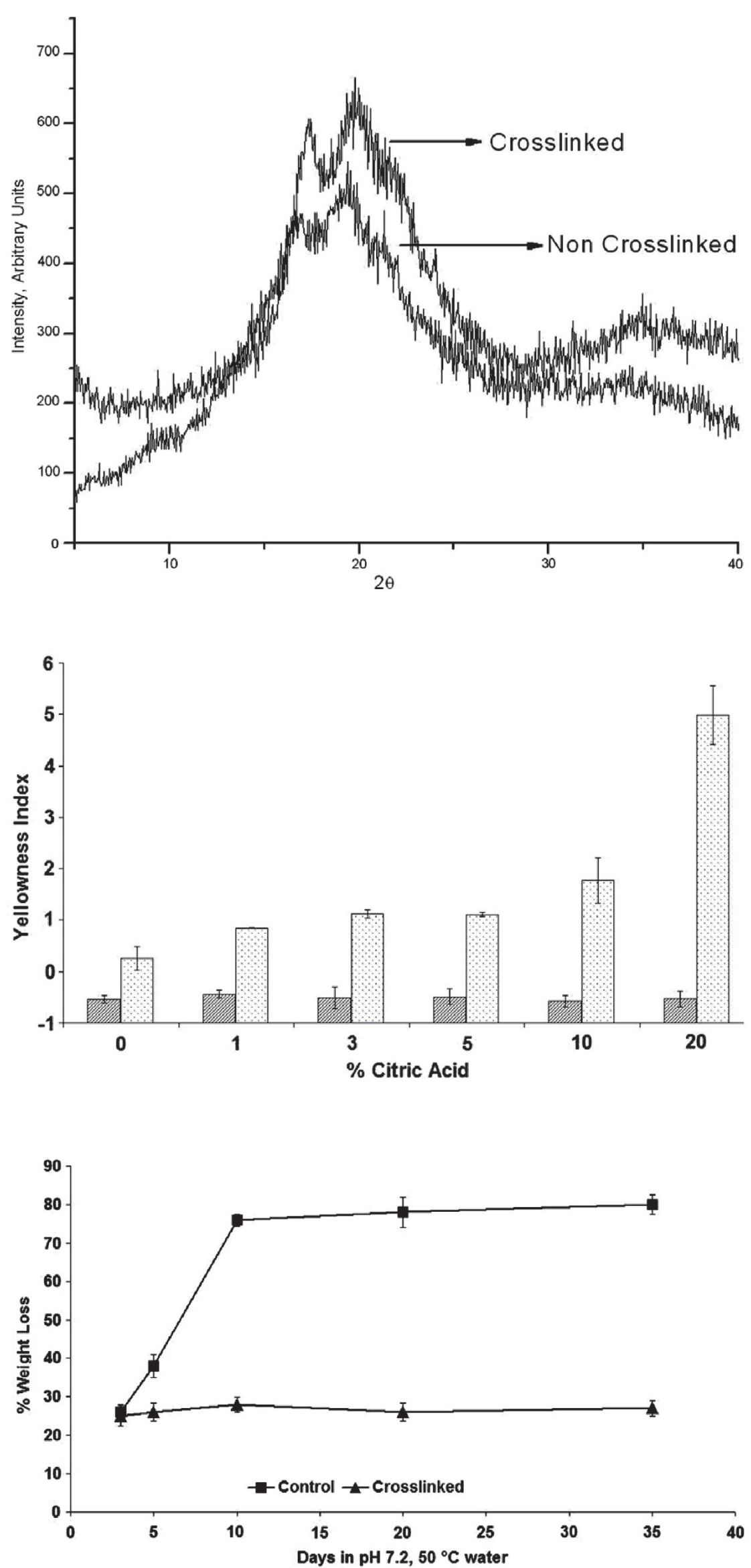
Figure 11. Weight-loss (\%) of the starch films after treating in formic acid at $20^{\circ} \mathrm{C}$ for $24 \mathrm{~h}$ and $50^{\circ} \mathrm{C}$ for $5 \mathrm{~h}$.

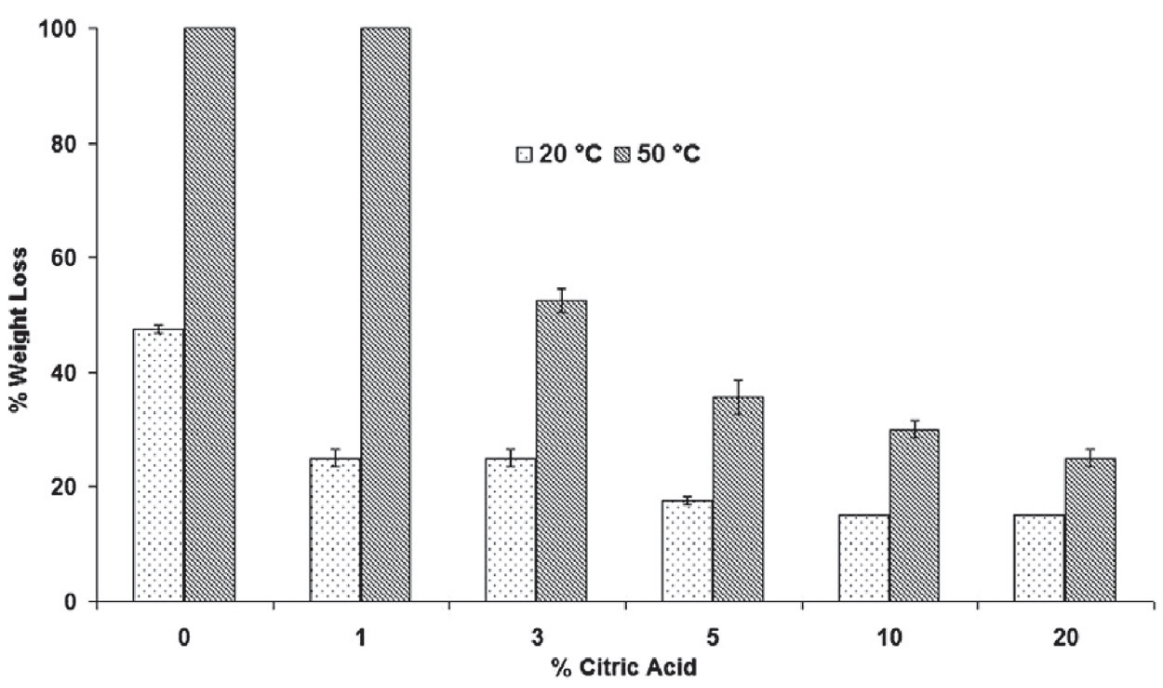

linked films lost only $30 \%$ and $25 \%$ of their weight after being in formic acid for $5 \mathrm{~h}$ at $50{ }^{\circ} \mathrm{C}$. The higher strength of the starch films and less swelling of the starch molecules after cross-linking should be the major reasons for the better stability of the cross-linked films in formic acid, compared to the non-crosslinked films. Although the $10 \%$ and $20 \%$ cross-linked starch films have lower strength than the $5 \%$ citric acid cross-linked films, the higher amounts of citric acid would prevent the dissolution of the starch in the $10 \%$ and $20 \%$ films, leading to better resistance to dissolution. The extent of citric acid to be used for cross-linking should therefore be selected based on the end use requirements for the films.

\subsection{Advantages of citric acid cross-linking}

Citric acid is preferable for starch cross-linking since low levels (5\% or less) are required for cross-linking; it can be derived from fermentation and could therefore be considered as a green chemical. Citric acid also has price advantages over a few other compounds commonly used to cross-link starch. Based on reagent-grade chemicals for laboratory purchase, citric acid costs about $\$ 0.05$ per gram, compared to $\$ 0.09, \$ 0.04$, $\$ 0.08$, and $\$ 0.07$ for glutaraldehyde, epichlorohydrin, boric acid, and sodium trimetaphosphate, respectively. From MSDS ratings, citric acid, boric acid, and sodium trimetaphosphate have health hazard rating of 1 , whereas glutaraldehyde is rated 2 and epichlorohydrin is rated 3. Sodium hypophosphite is reported to be hazardous to the environment. In addition to citric acid, other poly(carboxylic acids) may also be suitable for cross-linking starch films.

\section{Conclusions}

Citric acid effectively cross-links starch and improves the strength and considerably decreases the weight loss of the films in water and formic acid. Cross-linked starch films have about $150 \%$ higher strength than non-cross-linked films and also better strength than most cross-linked and/or synthetic polymer blended starch films previously developed. Crosslinked starch films show a broad melting peak and have considerably higher thermal stability (lower weight loss) compared to the non-cross-linked samples at temperatures between 320 and $600{ }^{\circ} \mathrm{C}$. Citric acid cross-linking slightly decreases the water vapor permeability and color $(Y I)$ of the films but the morphology and \% crystallinity of the films are not adversely affected. Starch films cross-linked with 3-20\% of citric acid have only about $15-25 \%$ weight loss, whereas the non-cross-linked films immediately dissolved in formic acid.

Acknowledgments - The authors wish to thank the Agricultural Hatch Act, and Multi-State Research Project S-1026 for their financial support.

\section{References}

Andrews and Welch, 1989 • B. A. K. Andrews and C. M. Welch, Efficient ester cross-link finishing for formaldehyde-free durable press cotton fabrics, American Dyestuff Reporter 78 (6) (1989), pp. 15-23.

Chen et al., 1997 - L. Chen, S. H. Imam, S. H. Gordon, and R. V. Greene, Starch-polyvinyl alcohol cross-linked film-performance and biodegradation, Journal of Polymers and the Environment 5 (2) (1997), pp. 111-117.

Garg and Jana, 2007 - S. Garg and A. K. Jana, Studies on the properties and characteristics of starch-LDPE blend films using crosslinked, glycerol modified, cross-linked and glycerol modified starch, European Polymer Journal 43 (2007), pp. 3976-3987.

Hirsch and Kokini, 2002 - J. B. Hirsch and J. L. Kokini, Understanding the mechanism of cross-linking agents $\left(\mathrm{POCl}_{3}, \mathrm{STMP}\right.$ and EPI) through swelling behaviour and pasting properties of cross-linked waxy maize starches, Cereal Chemistry 79 (1) (2002), pp. 102-107.

Kim and Lee, 2002 - M. Kim and S. Lee, Characteristics of crosslinked potato starch and starch-filled linear low-density polyethylene, Carbohydrate Polymers 50 (2002), pp. 331-337.

Kunaik and Marchessault, 1972 - L. Kunaik and R. H. Marchessault, Study of cross-linking reaction between epichlorohydrin and starch, Starch 24 (4) (1972), pp. 110-116.

Raj et al., 2004 • B. Raj, K. Udaya Sankar, and Siddaramaiah, Low density polyethylene/starch blend films for food packaging applications, Advanced Polymer Technology 23 (1) (2004), pp. 32-45.

Ramaraj, 2007 - B. Ramaraj, Cross-linked poly(vinyl alcohol) and starch composite films: Study of their physiochemical, thermal and swelling properties, Journal of Applied Polymer Science 103 (2007), pp. 1127-1132.

Rioux et al., 2002 - B. Rioux, P. Ispas-Szabo, A. Ait-Kadi, M. Mateescu, and J. Juhasz, Structure-properties relationship in crosslinked high amylose starch cast films, Carbohydrate Polymers 50 (2002), pp. 371-378.

Schramm et al., 2002 - C. Schramm, S. B. Vukusic, and L. Katovic, Non-formaldehyde durable press finishing of dyed fabrics: Evaluation of cotton-bound polycarboxylic acids, Coloration Technology 118 (2002), pp. 244-249. Research Division at the University of Nebraska-Lincoln, USDA 
Seker and Hanna, 2006 • M. Seker and M. A. Hanna, Sodium hydroxide and trimetaphosphate levels affect properties of starch extrudates, Industrial Crops and Products 23 (2006), pp. 249-255.

Simkovic et al., 2004 - I. Simkovic, M. Hricovini, R. Mendichi, and J. J. G. Soest, Cross-linking of starch with 1,2,3,4-diepoxybutane or 1,2,7,8-diepoxyoctane, Carbohydrate Polymers 55 (2004), pp. 299-305.

Wattanachant et al., 2003 - S. Wattanachant, K. Muhammad, D. M. Hashim, and R. A. Rahman, Effect of cross-linking reagents and hydroxypropylation levels on dual-modified sago starch properties, Food Chemistry 80 (2003), pp. 463-471.

Yang et al., 1991 - C. Q. Yang and B.A.K. Andrews, Infrared spectroscopic studies of the non-formaldehyde durable press finishing of cotton fabrics by use of polycarboxylic acids, Journal of Applied Polymer Science 43 (1991), pp. 1609-1616.

Yang and Wang, 1996 - C. Q. Yang and X. Wang, Formation of cyclic anhydride intermediates and esterification of cotton cellulose by multifunctional carboxylic acids: An infrared spectroscopy study, Textile Research Journal 66 (9) (1996), pp. 595-603.
Yang et al., 1997 • C. Q. Yang, X. Wang, and I. Kang, Ester cross-linking of cotton fabric by polymeric carboxylic acids and citric acid, Textile Research Journal 67 (5) (1997), pp. 334-342.

Yang et al., 1996 - Y. Yang, L. Wang, and S.J. Li, Formaldehyde-free zein fiber-preparation and investigation, Journal of Applied Polymer Science 59 (1996), pp. 433-441.

Yin et al., 2005 - Y. Yin, J. Li, Y. Liu, and Z. Li, Starch cross-linked with poly(vinyl alcohol) by boric acid, Journal of Applied Polymer Science 96 (2005), pp. 1394-1397.

Yoon et al., 2006v S. Yoon, S. Chough, and H. Park, Properties of starch-based blend films using citric acid as additive II, Journal of Applied Polymer Science 100 (2006), pp. 2554-2560.

Yoon et al., 2007 - S. Yoon, S. Chough, and H. Park, Preparation of resistant starch/poly(vinyl alcohol) blend films with added plasticizer and cross-linking agents, Journal of Applied Polymer Science 106 (2007), pp. 2485-2493.

Yu et al., $2005-\mathrm{J} . \mathrm{Yu}, \mathrm{N}$. Wang, and X. Ma, The effects of citric acid on the properties of thermoplastic starch plasticized by glycerol, Starch/Starke 57 (2005), pp. 494-504. 